\title{
Social "Smartourism": A Sustainable Development Methodology for Smart Urban Lands
}

\author{
By Michele Angelaccio* \\ Lucia Zappitelli ${ }^{\dagger}$
}

This paper presents a plan for a project called "Social Smart Tourism," which follows models of organizational development typical of Smart City, to plan strategies that, with the help of ICT technologies, will develop and optimize services related to human, intellectual, and social capital, involving information, communication, mobility and environment, in order to improve the quality of life. In particular, this paper engages with the methodology of "Smart Tourism," a much-promoted field oriented towards sustainable and environmentally friendly tourism, by underlining places and resources that are not well known. Then, the smart method is applied to the Social Tourism, leading to an innovative model of territory development, especially for more disadvantaged demographics such as the old, disabled, and poor. Social Smart Tourism arises from the need to accept the requests of territories regarding their requalification and from the necessity to fill the gaps of social aggregation. The suburbs of Rome, rich in hidden touristic resources of remarkable importance, distinguished itself among the territories analyzed by its demand of requalification. The stakeholders making the request are represented by the Ecomuseo Casilino Association and $V$ Municipio holding the territory of interest. The aim is to reintroduce a tourist-wise public park placed in the Comprensorio CasilinoPrenestino, which includes Villa De Sanctis and Casa della Cultura, promoting ancient discoveries that are in the park like the Mausoleo of S. Elena and the Catacombe dei Santi Pietro e Marcellino. In this work, we present this example of request and planning through a model of a smart village, defined in cooperation with the Smartourism Laboratory and based on concepts and methods for the realization of new ICT infrastructures and sustainable socio-economic models. This coincides with the introduction of an example of cultural parameters oriented to resolve the difficulties of connection and participation inside the territory.

Keywords: Smart City, Sustainable Tourism, Project Management, Peripheral Areas, Social Tourism.

\section{Introduction}

Accepting territorial requests from the suburbs regarding their urban requalification, especially in terms of a necessity to fill the gaps in social aggregation that are missing in these chaotic and degraded urban lands requalification projects, often requires a multidisciplinary approach in order to

\footnotetext{
* Associate Professor, Management Engineering Department, University of Rome Tor Vergata, Chair of Smartourism Research Laboratory, Italy.

${ }^{\dagger}$ Communication Manager, Smartourism Research Laboratory, Italy.
} 
enact real change at the social level, thus helping people to be actively involved. In the outskirts of Italian and European cities (e.g. Rome), this approach is not only desirable, but it also is the simpler and more direct way because of the existence of large abandoned territories, for which sustainable development typically occurs only through the requalification of museum areas and the valorization of territories that show themselves as potential open-air museums. In this context, urban requalification takes the shape of projects that go beyond the scope of Smart City and are better defined as Social Smart Tourism projects, which complement each other through smart ICT methodologies and social inclusion models. This makes cultural associations and laboratories of technological research cooperate in order to realize an actual multidisciplinary relationship between designers. Particularly regarding Rome, this paper focuses on cases of peripheries (Roma est casilino), as well as on several collaborations between the cultural association Ecomuseo Casilino and the Smartourism laboratory called Turismopoli from the department of Engineering Management, Tor Vergata.

New technological models, like IoT (Internet of Things), allow us to expand and improve the touristic supply involving the inhabitants who, when taught about this new technology, are able to be a reference and resource for visitors (i.e., guides in the territory supporting the use of these new technologies).

\section{Ecomuseo Casilino}

The Ecomuseum is a cultural association (Ecomuseo, 2017) based on a territorial agreement between communities through which citizens endeavor to take care of an area by preserving and enhancing its cultural, historical, and environmental values. This is achieved by augmenting, rather than consuming, existing resources in a sustainable way. In this way, the territory is viewed as a collectively designed space to be enhanced, protected, and developed through innovation while also preserving its existing identity.

After preliminary exploration, the territory of interest will be configured as an important resource in participatory and shared projects. These projects will establish and enhance the territory as a relevant area of the city, rich in both evidence of ancient times, natural resources, and historical memories.

The aim of the methodology is to improve the quality of life of the urban periphery in the following ways. The first motivation is to connect with cultural things in the local area by making them accessible and adding values. This will also improve quality of life in the suburbs through the insertion of aggregation social points in the hungry land and the writing of historical documentations for discussions, sharing and rediscovery of stories, thus allowing a positive sense of belonging and acknowledgement. The expected result will be the reduction of the fragmentation and scattering of inhabitants in the territory, thus improving the ability to understanding with a social action in 
the living place. This is similar to the vision claimed in the work of Baumann (2002), in which he introduces the notion of glocalism.

Thus, this project fills an existing void in references, meanings and stories of a community, consequently investing in the social capital of a territory.

This methodology is opposed to the perspective of a faceless and placeless power given to economic and cultural globalization, by encouraging communities to reclaim possession of their history and identity.

Figure 1. The Impact of Social Smart Tourism in Suburbs
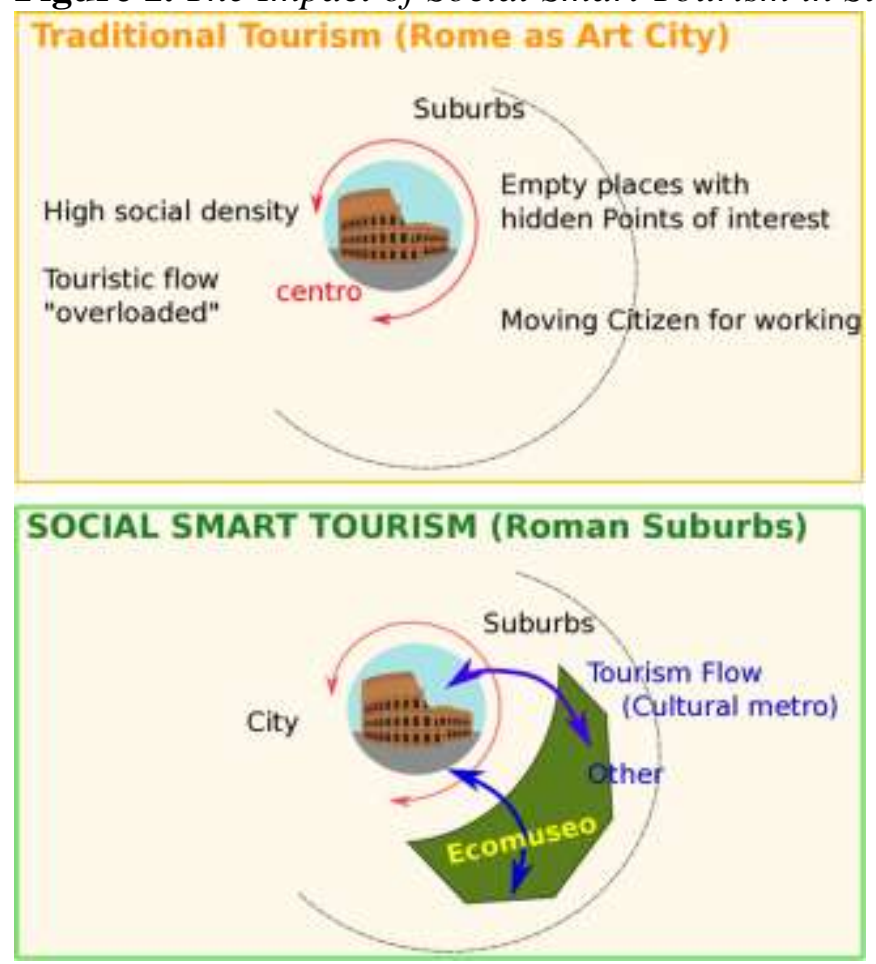

The Smartourism Research Laboratory "Turismopoli” is a project lab working to design conceptual systems and services to support touristic networks. This lab was launched two years ago by Professor Angelaccio, who is the coordinator, and now is managed by a set of people working in different fields. Several workshop and conferences have been organized with contribution from Digital Tourism and Tourism Management research areas. As a result, they developed a web system with local internet suitable for digital destination implementation (Digital Niches of Tourism) for which the results are given in the paper Angelaccio et al. (2016). Preliminary demonstrations have been displayed in concrete examples of Social Smart Tourism, such as the case shown in this work. In fact, in the case of the Roman peripheral area, the Smartourism Lab proposed as an aggregation centre to enhance tourism factors that are either hidden or unused. 


\section{Literature Review}

Ishmael Mensah (2016) shows the importance of the presence of the local community in tourism for the growth of economical and social welfare, as well as for sustainable handling of natural and cultural resources. For example, Community Based Ecotourism Projects (CBEPs) models of touristic projects, in collaboration with the National Conservation Research Center (NCRC), have seen great success. By giving territory management directly to local teams of citizens, they produced an increase in socio-economic welfare and personal empowerment. Ecotourism also facilitates the preservation of the environment and mitigates poverty in rural communities, in particular in national parks and protected areas. Participation in the development of tourism motivates people's conservation of environmental resources, even if environmental benefits are not seen as significant for their own quality of life, for example for the increase of income from tourism. Thus, the participation of everyone is necessary for the effectiveness of touristic projects.

Moreover, it is evident that social bonds are key factors that feed skills in the management of natural resources. In the end, the socio-cultural impact of tourism is positive, but it does not originate from a relation with tourists, with whom there is no communication or participation. In the dissertation $A$ model of slow mobility for the touristic and territorial integration of the Città Metropolitana di Venezia (Alfier, 2015), another touristic model is quoted: the Tourism $d u$ Territoire (local Tourism). This model includes climatic, environmental, and cultural factors that shape the territory and use its resources in a specific way, in particular those that are hidden or little known. By "culture," we mean every material and immaterial resource that marks the identity of a local community. Bauman, a renowned sociologist, in his work Society under Siege, compares economic and cultural globalization to the newly born phenomenon of "glocalism," or a rediscovery of your own identity and your own roots within a global context. It is bound to the territory of origin in order to recover essential reference points for the human being. The table shows the social touristic involvement degree from urban people categories for each of the cases. It represents the case of Rome, which requires a lot of attention.

Table 1. Social Categories and their Involvement in the Social Tourism

\begin{tabular}{|l|l|l|l|}
\hline \multirow{2}{*}{ Categories } & Natural Parks & Suburbs & $\begin{array}{l}\text { Local } \\
\text { Tourism }\end{array}$ \\
\cline { 2 - 4 } & Ghana & Rome & Venice \\
\hline Tourist & Low & Low (hit and run) & Good \\
\hline Resident & Good & Very Low & Good \\
\hline
\end{tabular}


In the next, we see that the social smart tourism will allow a better relationship among tourists and residents with the aim of a better cultural exchange.

\section{Methodology}

The concept of Smart City has been used to cope with the problem of making our cities more efficient by introducing both new types of artificial intelligence through innovative technologies and infrastructures, as well as new investment in human capital for social and economic reorganization of local communities (thus leading to an integrated model of development factors for the Smart Cities).

Because Rome is a city with many artistic and cultural sites, urban development is mainly based on tourism in the sense that businesses strongly depend on touristic flows. Therefore, it seems reasonable to adopt a methodology based on the Smart City approach through technologies and models related to Smart Tourism and social perspectives, thus making artistic cities more accessible (Smart Art City).

In fact, the absence of "Smartourism" strategies in the last years has incremented mass tourism without balancing the city with suburbs flow and making social life difficult due to unsustainable and invasive tourism. In this way, suburbs may be abandoned without any development planning, even when there are a lot of hidden touristic resources.

The need to develop smart cities in a faster and more concrete way suggests that the tourism sector could be used as a driving force for the application of new methodologies. This has been also evidenced in the work (La Rocca, 2014).

Hence, a more suitable development approach is to allow local people to participate in tourism projects in order to improve their quality of life through the expansion of services, including access to tourist resources, services, and ICT (smartourism). In addition, they also promote those forms of tourism suitable for citizens of all categories, especially the weakest (social tourism), allowing affordable as well as sustainable and accessible tourism (social tourism or tourism for all).

Among the examples that will be described to illustrate the methodology, we consider two main cases. The former is given by a sustainable urban transport service model that realizes a service "smartourism" cultural subway or cultural tram. This solution, by revitalizing its use in terms of sustainable tourism, makes efficient part of the existing transport and regenerates a service territory that otherwise would have been abandoned. Thus it removes from the community most of its history and also has a negative impact on territorial identity. The latter is instead given by a novel conceptual model introduced to better integrate the different aspects of smartourism and social tourism and is called smart village model. A smart village is provided with infrastructure of distributed digital museum, which is introduced to make available content 
related to green area with historic monuments. Such smartourism initiatives are coordinated in response to requests by the stakeholder and based on the territorial agreement with the local community (Ecomuseum). This will facilitate the land care and knowledge for the local community (and not only for researchers).

The impact of such projects on the territory is sustainable and aims to eliminate the degradation and social isolation of the periphery by improving cultural resources.

Smart Social Tourism includes two models of cultural development for tourism purposes that share a psychological orientation aimed at creating a better quality of life and greater prosperity. These models are as follows.

The Smart City methodology applied to tourism will define Smart Tourism and is characterized by a sustainable tourism, supported by digital technologies that help citizens to be better involved in touristic projects and give better perceived services and an increase in income and quality of life. Moreover, this would increase satisfaction index and participation in all planned activities related to tourism. People with disabilities and weaknesses (e.g. elder people) can better access touristic resources in their land through custom projects and thus participate in tourist activities.

Another important model is given by the Ecomuseum, which is a social and cultural development model of the territory based on a pact with the local community, in order to take care of the territory itself and preserve and enhance the cultural heritage, environment, and natural resources rather than consuming the value through the recovery of hidden resources and telling the history of that territory from the point of view of the origins, traditions and local culture. This will increase the sense of identity and belonging (psychological function) in accord with the principle that the degree of development of a land is given by the level of education and empowerment of its citizens (Smart City).

The idea of integrating these two models comes from the aim to obtain a methodology that can be applied in areas where there are open green spaces (parks, archaeological sites, historic districts, or memory spaces), but with an additional kind of social implication applied to each model. These analyses and implications must also include a consideration of the most disadvantaged people in order to be successful for both the tourist and the tourism project administrator.

\section{Smart Issues of the Methodology}

The need to obtain a smart city project requires that workers cooperate in a strict and sustainable way (co-working). This implies a sequence of steps in project phases that are designed in accord with the S.M.A.R.T. (Specific, Measurable, Achievable, Realistic, Time-constrained) model to reduce risks. Therefore in our project proposal, the SMART methodology can be applied to 
Social Tourism yielding a novel development model of the land for tourism purposes.

Table 2. Social Smart Tourism Model

\begin{tabular}{|l|l|l|l|}
\hline SOCIAL & SMART & TOURISM \\
\hline Who & How & What \\
\hline $\begin{array}{l}\text { Disabled people, } \\
\text { elders and people } \\
\text { with low income }\end{array}$ & $\begin{array}{l}\text { Welfare and cultural associations } \\
\text { with innovation methodologies } \\
\text { supported by ICT technologies }\end{array}$ & $\begin{array}{l}\text { Cultural and } \\
\text { naturalistic Context } \\
\text { with emphasis on } \\
\text { typical products }\end{array}$ \\
\hline
\end{tabular}

\section{SMART Project Phases}

The project manament organization that we consider is given by a set of Smart project phases. These are organized in the following way:

1. Land Requirements Analysis, which is defined in accord to resources, roles and functions. The communicating activities will be related towards stakeholders and other governments with the aim of reducing risks.

2. Planning Analysis, which is carried out by WBS (Workpackage Breakdown Structure) and definitions of role matrix (OBS) through for example meeting/coworking in the ecomuseum

3. Executing Process or Workpackages Definition Process through application of WBS to the defined OBSs. Such implementation will be ususally done through CPM (Critical Path Methods) technique based on temporal diagrams, logical networks with milestones.

4. Project Budget Control Processes and Test Analysis through risk factors with cost estimation and payment schedule (TSC Time Scheduling Constraint).

Considering the example of the Roman suburbs, under the hypothesis of involving the Ecomuseum and stakeholders connected to it, we can assume a CENTER PROJECT (in the real case will be the Laboratory of Smartourism) of Smart Social Tourism for the coordination of project phases specified above:

- For each Specific territorial problematic, even at the social level, you can define one or more goals to be pursued by WP.

- Each issue is Measurable according to planning, and the boot process, start, estimates, activities etc.

- The subsequent execution requires that both be actually Achievable. This means that they should be in accord with the given temporal scheduling, thus minimizing the risks through monitoring. That is particularly suitable in the context of social tourism projects since the active participation of residents who feel involved ensures greater 
control of the execution process by also conducting field activities (markets, social events, etc.) that are time coordinated in according to the traditions.

- Moreover, Realistic concerns with the extraction of cultural values and territorial interest that would otherwise be abandoned and hidden, even to protect a historical and cultural heritage.

- Finally, the Time-constraint is guaranteed by the maximum duration of the project, which imposes a limit that cannot be exceeded. Also this feature can be achieved safely in contexts of social tourism eliminating weaknesses (avoiding unnecessary red tape related to authorization) and exploit the strengths (the maturities of social events, seasonality of markets).

\section{Ongoing Activities}

The stakeholders that make the request are the $\mathrm{V}$ Municipio and the "Ecomuseum Casilino" Association. Both are interested in requalifying a park in the district Casilino-Prenestino, which includes Villa De Sanctis and the House of the Culture (Casa della Cultura), enhancing the archeological sites (Mausoleo di S. Elena, Catacombe SS Pietro e Marcellino) inside, and creating an oasis within the chaos of the district. This project could be an important point of social aggregation for cultural events and local handcraft markets, games, street art, street food, bicycle paths. Projects could also include preferential lanes for the old and disabled to access archaeological sites, or simply to go around the park via shuttle bus, all with the help of properly educated staff.

Moreover, the park plans to host ethical purchasing markets, supported by social farming or welfare cooperatives, which allow needy social demographics to join in touristic-oriented projects, thereby increasing the feeling of belonging to a community and their own empowerment.

The project aims to optimize already existing resources and to increase the environmental sustainability factors influencing the impact of projects on the land.

Finally, an urban transport service has been reactivated around the park (Metro Culturale) through an existing historical tram from the 1920s, which was used for urban service until some years ago when it was replaced by the underground $\mathrm{C}$, supported by ICT technologies that enhanced its track going through important archeological finds.

Hence, the Metro Culturale (Cultural Tram) is an example of increased welfare and sustainable mobility for citizens and tourists by means of ICT technologies.

Smart City service elements and infrastructures require significant use of new and more sustainable technologies, which have to be able to operate in urban and metropolitan territories. 
In urban contexts which are very rich of touristic potential, such as the outskirts of Rome, there is the further difficulty of bumping into areas that are difficulty to make "smart."

This paper provides a first example of touristic transport model, which integrates a particular touristic mobility solution with sustainable intermodal transport, fitting the suburbs of Rome.

The idea came from a former proposal in the 1960s, in which appeared the feasibility of an example of a Cultural Tram (ArcheoTram). In this period, no one knew whether those rail transport lines around the east outskirts of Rome should be dismissed or requalified into something new.

This model brings this initiative back, reformulating it for a modern view of territorial web-gis, in which it is proposed that sustainable transport will be realized, for example, with buses connecting the lines of the underground, following historical and cultural tracks through urban parks in the east outskirts of Rome. This model is based on the introduction of a digital niche model, according to an informatic model of web-transport. These tracks have stopped near historical and cultural sites and go through districts and parks in a "ondemand" manner. In this way, multi-purpose infrastructures, both of sustainable transport and of mobile-web informative touristic systems, is realized.

A possible project set-up in such scenarios corresponds to the Roman suburbs: a first connection ring between Metro $\mathrm{C}$ and the streets Prenestina and Casilina, as well as a second one between Metro A and the Casilino Parks, allows safe access with shuttles to the parks themselves. This allows a better urban lifestyle that is tuned in with the existing transport streams of underground lines.

The stops are placed at many points of interest (mausoleums, catacombs, spas, and ancient artifacts from ancient Rome and the medieval period) that form the urban totem for metropolitan tourism, but also operate as a shuttle for cultural and trade events of the diffuse type.

The use of such a service is controlled by a management system on demand and it is also organized on the basis of different user categories (elderly, disabled, families with children, etc.). This keeps in mind district tourism purposes in addition to those of outside tourists.

The operating model and the platform of the web encourages the use of such technologies as transport simulations on Google Maps and smartphone interfaces.

In particular, the model can also be applied during or set of small events on different areas but which could be aggregated into one widespread event. In these cases, the cultural metro can also be used as an event shuttle-bus.

It is also necessary to introduce a governance network that goes beyond the eco-museum to involve the town hall and local governments. For example, in the case of the cultural metro, it must hold that the directors cooperate by sharing a common interest in improving land efficiency, and consequently the services offered to citizens. 


\section{Findings/Results}

The expected results can be grouped in two classes:

1. Social requalification factors

2. Development opportunities

For the first case we have a better citizen participation, or a stronger connection with incoming activity on the territory and the enhancement of cultural and environmental resources. In addition it holds a greater knowledge of the territory and better motivation to take care of improving the visitorresident communication which becomes more welcoming and less passive facilitating the sharing of their cultural heritage, environmental and artistic and local customs and costumes. These facts can improve the quality of life in the sense of people are being involved in tourism projects and have greater economic welfare perception yielding an higher customer satisfaction and improved services. Moreover we obtain a better mobility system with passenger flows that are easily dislodged from the periphery to the center and vice versa with the opportunity of interacting with hidden tourist resources. From the social point of view it is important to remark that a double inclusion objective can be obtained. Not only tourist use for disadvantaged groups (disabled, elderly and low-income groups), but also their involvement in tourism projects and activities through welfare associations or cooperatives that provide their tools and their areas (e.g. social agriculture, sustainable crafts, solidarity markets and typical food services).

Concerning the working and development opportunities, we must also note that transfer and mobility opportunities related to tourism and sustainability (electrical bus and bikes, etc.) can be obtained, giving the chance to extend working capabilities in this field that otherwise have been greatly reduced in recent years. In addition, further opportunities are given by ecotourism working spaces also considered available for disabled and disadvantaged people. From an anthropological point of view, Rome gives the opportunity to rebuild ancient areas like Trastevere roads and squares that could be revitalized in other suburbs by reconstruction of "typical people on the road stile of life" obviously in a safe context (such as a movie context).

Moreover note that the SST project methodology adopts the Agile Project management due to social needs and requirements. This would allow the capability to add new coordinators for interacting with the project phases inside the Smartourism Lab team.

\section{Discussion}

The SST methodology and its innovation issues are related mainly to the fact that it gives the chance to be included both to disadvantaged people (social tourism) and to citizens (the elderly and low-income), allowing those who 
normally are outside the main tourist flows to take an active part in "hospitality and tourist hospitality management" thereby improving the experiential quality of tourism.

Tourism, in general, produces improvements in relations between people, thus creating solidarity, social and cultural growth, and social tourism. It also allows the most disadvantaged groups to take advantage of good relationships and to leave the solitude of a liquid society (i.e. without references to traditional values).

In addition, the adopted smart approach will give the opportunity and the capability of using the same cultural heritage through mobile technologies based on the paradigm of the "Internet of Things." This makes it easier to create a digital community in urban areas, especially for young people who now are digital natives and often make use of smartphones to communicate and organize leisure activities.

Compared to the methodology illustrated in the work (Mensah 2016) the proposed SST methodology allows cultural empowerment that goes beyond the environmental and economic aspects typical of natural parks management. The degree of urban land development is also given at the level of education and awareness of its citizens. Cultural education in languages predisposes a region to more effective communication between tourists and local citizens, with increased capacity for hospitality and courtesy. Tourism is no longer seen in a passive way, or an invasive way, but as a proud sharing experience of cultural and environmental heritage, thus facilitating the development of human relationships.

Compared to a bike-sharing project in Veneto, we can see, beyond the similar fragmentation of things, a cultural difference from the point of view of the community lifestyle. In fact, for each community the way that health and sports are practiced and adopted is very different. For instance, there is a highlevel practice case in the Veneto region, including by women and old people, while on the other hand, a similar level is difficult at present in the Lazio area where car traffic results in stress and pollution.

This is also caused by urban planning traffic that is the result of incorrect and chaotic urban planning, often of an abusive (or unauthorized) type.

It would be interesting to spread healthy good practices aimed at quality of life and linked to an urban renewal even in the Lazio region in the long term. In the short term, people could overcome problems through the massive use of public transportation such as shuttle buses and the metro (cultural). This is aimed also in the direction of slow tourism for the local area with respect to the invasive and unsustainable mass tourism especially for the actual Roman car traffic state.

Cultural heritage, especially in the way that it spreads knowledge, is the most viable way to go back to those traditional references "solid" which often are abandoned. They could be re-invented through a new idea based on a modern and relaxing access strategy such as tourism, with the aim of developing and sharing assets and their own history, enhancing identity and 
belonging, and looking to different cultures with a purpose of building together and overcoming cultural divisions.

The "liquid society" thereby solidifies itself with awareness and selfefficacy by taking charge of its own future and developing a new "smart community."

\section{Conclusions}

The idea of the Smart Social Tourism project stems from the need to accept the territorial question regarding the restructuring of the Roman suburbs and the need to fill the void of social aggregation with particular reference to the most vulnerable social groups such as the elderly and disabled.

The stakeholders, here the Ecomuseum Casilino Association and the municipalities, have shown through their interest in the territory that there is a serious lack of adequate facilities and services for social gatherings, especially within the Park Villa de Sanctis.

This territorial application has been recently utilized by the Laboratory of the University of Tor Vergata Smartourism TURISMOPOLI (Management Engineering) to support local governments in the planning and execution of design ideas in tourism with the help of ICT technologies.

The basic applied methodology given by Smart Tourism considers as an organizing model the land on the basis of smart processes built for touristic development in areas still outside of current touristic flows. It is derived from the Smart Cities methodologies applied to the cities of arts to improve visiting rates.

The acronym S.M.A.R.T. stands for Specific, Measurable, Achievable, Realistic, Time-constrained.

When it is applied to original objectives, the methodology extracts weaknesses and critical points together with positive facts in an easy way.

In this work, the Smart Method is applied to the concept of SOCIAL TOURISM, thereby yielding a new and sustainable development model for tourism strategies even for the most vulnerable social categories.

Social Tourism (tourism for all) is the result of a new concept of tourism viewed as a responsible and sustainable initiative for the community involved and is targeted to the most disadvantaged groups such as disabled people and low income. It is centered on the satisfaction of social inclusion needs and ensures the inalienable right to leisure and relationships, thus escaping the logic of tourism "hit and run."

Within the archaeological park, cultural items will be viewed and revised through digital infrastructure equipment and tags over the main points of interest within digital niches. They will be accessible to users via bus shuttles that run through cultural routes also with lanes for the most vulnerable. Furthermore, it will be provided the upgrading of the park to create appropriate social gathering spaces with cultural events and craft markets and supportive. 
The park has an area of 12 hectares, including areas yet to be reclaimed. It is linked to Termini station through the Laziali-Centocelle train line and Metro C. It is currently used rarely and has no rest facilities, such as benches and playgrounds for children. The goal is thus to revitalize the park from the archaeological, cultural, and social points of view by developing tourist offerings.

Participation in tourism projects by local communities creates development in urban areas in terms of human capital by increasing their income, quality of life, and sense of empowerment.

The contribution of cultural associations is very important in local communities, as it involves the knowledge of their historical, cultural and anthropological heritage. Increases in a sense of belonging, identity, and selfefficacy, improve communication and the relationship between tourists and residents. These also optimize the tourist experience with greater satisfaction in terms of hospitality, because the residents can share their resources with others and promote the integration of different customs and practices.

These aspects of development refer to the growing phenomenon of glocalism, meaning the rediscovery of roots as opposed to the globalization phenomena of faceless and placeless power (Identity Loss).

The expected results are innovative in their specificity, while also drawing on resources already present, in order to optimize and develop the environment in a sustainable way. Redesigning the suburbs of the city is an important step for the development of urban areas, an inclusion that invites institutions to be more invested in urban infrastructure and human capital, particularly with regards to a Smart City.

\section{References}

Angelaccio M and Buttarazzi B (2016) Street Web-A Framework for "Web on the Road" Smart Services. WEBIST Conference 2016.

Mengardo G, Van Der Vorst J (2016) Il Turismo Accessibile a Venezia. Un "Isola Dell'Accessibilita" Attorno ai Musei Civici per Una Cultura Senza Barrier [Accessible Tourism in Venice. An "Accessibility Island" Around Civic Museums for a Barrier Free Culture]. Thesis degree Univ. of Venice Ca' Foscari.

Alfier M (2015) Un modello di mobilità slow per l'integrazione turistica e territoriale della Città Metropolitana di Venezia [A Slow Mobility Model for the Tourist and Territorial Integration of the Venice Metropolitan City]. Thesis degree Univ. of Venice $\mathrm{Ca}^{\prime}$ Foscari.

Mensah, I (2016) Effects of Socio-Demographic Characteristics and Perceived Benefits of Tourism on Community Participation in Tourism in the Mesomagor Area of the Kakum National Park, Ghana. Athens Journal of Tourism September 2016.

Baumann Z (2000) Liquid Modernity.

Baumann Z (2002) Society under Siege.

Ecomuseo. (2017) Available at: http://bit.ly/2m55VEt 
Vol. 4, No. 2 Angelaccio et al.: Social "Smartourism"...

La Rocca R (2014) The Role of Tourism in Planning the Smart City. Journal of Land Use, Mobility and Environment. 